\title{
Comparative analysis of surgical outcome of treatment of supracondylar humerus fractures Gartland's extension type III by using closed reduction and $K$-wire fixation versus open reduction and $\mathrm{K}$-wire fixation method
}

\author{
Nilesh Janardan Keche, Abhijit Bhimrao Kale*, Binoti Arun Sheth, Ashok Kumar Rathod
}

Department of Orthopaedics, Lokmanya Tilak Muncipal Medical College, Sion, Mumbai, Maharashtra, India

Received: 11 December 2016

Accepted: 30 December 2016

\section{*Correspondence:}

Dr. Abhijit Bhimrao Kale,

E-mail: drorthoplanet@gmail.com

Copyright: (C) the author(s), publisher and licensee Medip Academy. This is an open-access article distributed under the terms of the Creative Commons Attribution Non-Commercial License, which permits unrestricted non-commercial use, distribution, and reproduction in any medium, provided the original work is properly cited.

\section{ABSTRACT}

Background: Supracondylar fractures of the humerus are the most common elbow fracture in children of the age group 4-12 years. The modern approach for its treatment includes closed reduction or open reduction and internal fixation with $\mathrm{K}$ wires. The aim of the present study was to evaluate the clinical and radiological results of children who were treated with the two surgical approaches.

Methods: In our institute children who underwent surgical treatment for supracondylar humeral fractures by closed reduction or open reduction and internal fixation with $\mathrm{K}$ wires and whose data were available with regular follow-up of at least 1 year were included in the study. Each group included 25 children in each. Clinical and radiological outcomes were evaluated and compared among the study groups.

Results: The mean age of the patients in both the groups were 6.84 and 6.64 in group 1 and group 2 respectively. Fractures were more in boys compared to girls in both the groups. Most of the fractures were seen on left side with posteromedial displacement of distal fragment in almost $80 \%$ in both the groups. Mean change in Baumann's angle (BA), carrying angle and range of motion (ROM) as compared to normal side in both the groups after $3^{\text {rd }}$ and $9^{\text {th }}$ month of follow ups was found to be not statistically significant. Overall result according to Flynn's criteria was $60 \%$ excellent in group 1 as compared to $52 \%$ in group 2 . Mean satisfaction score was also more in group 1 children when compared to group 2.

Conclusions: Closed reduction with internal fixation with $\mathrm{K}$ wires was found to be a better choice of treatment with good functional results.

Keywords: Supracondylar humerus fractures, Closed reduction, Open reduction

\section{INTRODUCTION}

Supracondylar fractures of the humerus are the most common elbow fracture in children and makes up approximately $60 \%$ of all elbow injuries. ${ }^{1,2}$ According to Boyd and Altenberg, these fractures account for $65.4 \%$ of upper extremity fractures in children. ${ }^{3}$ Peak age of occurrence is in first decade of life and it became progressively more uncommon as the child approaches adolescence the average age group of patient being $71 / 2$ years. $^{4}$ The main cause for this fracture is fall on outstretched hand and indirect injury to elbow. ${ }^{5}$ Left non dominant side is most commonly involved. ${ }^{6-8}$ On the basis of displacement of distal fragment supracondylar fracture divided in to extension and flexion type of which extension type account for $97 \%$ to $99 \% .{ }^{5}$ It is further divided in to posterolateral and posteromedian displacement, posteromedian displacement is common in $75 \%$ cases. $^{9}$ 
The traditional treatment with closed reduction and application of plaster slab or cast is inappropriate in the management of supracondylar fractures of the humerus as this method is potentially hazardous to circulation, as it may enhance circulatory insufficiency which is already hallmark of supracondylar humerus fracture and it is difficult to obtain satisfactory reduction and to maintain the reduction. Hence, surgical management like percutaneous pinning after closed reduction or open reduction and internal fixation with $\mathrm{K}$ wires plays an important role in this type of fractures. Closed reduction for extension Gartland's type III supracondylar fracture of humerus has given new window of management which is excellent method.

Open reduction of supracondylar fractures extension Gartland's type-III lead to, visualisation of the traumatic anatomy, restoration of the pillars and the fossae and maintenance of pillar heights by cross $\mathrm{k}$ wire fixation ensure a predictable good cosmetic and a functional result. Also this method allows elbow extension for comparison of carrying angle and correction of medial or lateral tilt during the surgery. ${ }^{10,11}$

The purpose of study was to compare the surgical outcome of treatment of supracondylar humerus fractures Gartland's extension type III by using closed reduction and $\mathrm{K}$-wire fixation versus open reduction and $\mathrm{K}$-wire fixation method.

\section{METHODS}

This was a prospective observational study conducted at our institute during the period of two years. This study included 57 patients after meeting the requirements of the study. But 7 patients were lost to follow up. Hence, a total of 50 patients with supracondylar humerus fracture extension type III below the age of 12 years were included in study after getting approval from institutional ethics committee. Patients with poor general condition and haemo-dynamically unstable were excluded the study.

All patients of supracondylar humerus fracture extension type III, are admitted within the period of study were identified from trauma registry and hospital records. Out of 50, 25 patients were operated by closed reduction with $\mathrm{K}$ - wire fixation and 25 patients were operated by open reduction with $\mathrm{K}$ - wire fixation. All patients were observed, followed up and evaluated up to 9 months. All demographic details of the patients were noted on a proforma.

\section{Clinical assessment}

Detailed history of mode of injury was obtained from the parents, as well as the patients. Clinical assessment of all supracondylar humerus fracture extension type-III, was done in the term of age at presentation, mode of injury, time since injury, associated neurovascular deficit,
Brachialis sign and associated injuries. Also postoperative assessment was done in term of range of motion, surgical wound healing, postoperative complications like deformity, ulnar nerve injury, nonunion if any. All collected data were compared in both treatment groups.

\section{Radiological assessment}

Radiological assessment was done to find the anatomic location of fracture, flexion or extension, fracture according to Gartland's classification, the displacement of distal fragment posteromedial or posterolateral, medial communition or not. Preoperative AP, and lateral radiographs were taken and assessed all fractures in the form of postoperative Baumann's angle and anterior humeral line and compared it with normal side. Also radiological appearance of callus and radiological duration for complete fracture healing postoperatively, in both treatment groups were compared.

\section{Operative technique}

Preoperatively patients were properly examined and consider fit for surgery. Under general anaesthesia with patient in supine position with affected limb on side arm support table, for closed reduction procedure. For open reduction procedure lateral position given and affected elbow supported on a sand bag and it was left free on the side of the table, tourniquet was applied. Then the elbow with distal arm painted and draped. We have done closed reduction technique in supine position and fixation and for open procedure group we have exposed the fracture site by using midline posterior incision with para-triceps approach for open reduction group. And fixation was done by using cross $\mathrm{K}$ wire for both group patients. Post operatively $\mathrm{A} / \mathrm{E}$ slab is given in slight extension to all patients. Postoperative protocol of IV antibiotics, $\mathrm{k}$ wire removal, physiotherapy kept same in both group.

Functional and cosmetic results were graded based on Flynn et al criteria as given in Table 1 and satisfaction score $(0-10)$ is studied by using blinded evaluator and patients perspective score.

\section{Table 1: Flynn's criteria for assessment of surgical} outcome.

\begin{tabular}{|lll|}
\hline Rating & $\begin{array}{l}\text { Loss in carrying } \\
\text { angle }\end{array}$ & $\begin{array}{l}\text { Loss in elbow } \\
\text { movement }\end{array}$ \\
\hline Excellent & $0-5$ & $0-5$ \\
\hline Good & $6-10$ & $6-10$ \\
\hline Fair & $11-15$ & $11-15$ \\
\hline Poor & $>15$ & $>15$ \\
\hline
\end{tabular}

\section{Follow-up}

All patients were followed up periodically, functionally and radiologically. Outcome analysis was done at 2 
weeks, 3 weeks, 1 month, 2 months, 3 months, 6 months, 9 months to maintain uniformity and allowed for comparison amongst different groups as shown in Figure 1 and 2.
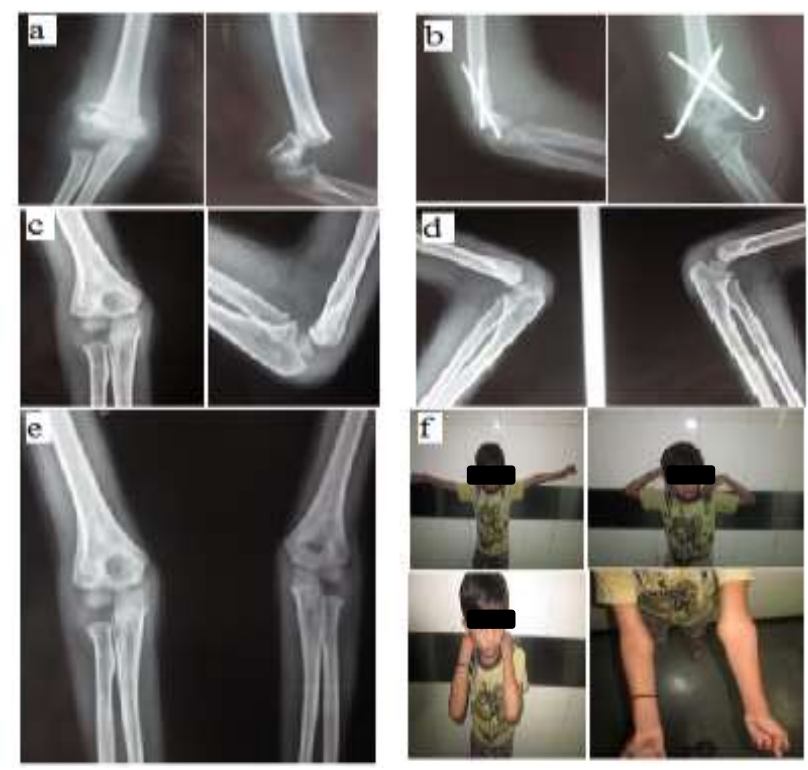

Figure 1: 5 year old boy with fresh closed, supracondylar humerus type III fracture treated with closed reduction and internal fixation by using cross $k$ wire. (a) preopeartive X-ray, (b) immediate postopeartive X-ray, (c) \& (d) X-ray after 9 month

follow up, (e) calculated Baumann's angle and comparison with normal side, (f) clinical pictures of flex-ext movement, scar and carrying angle after 9 month follow up.

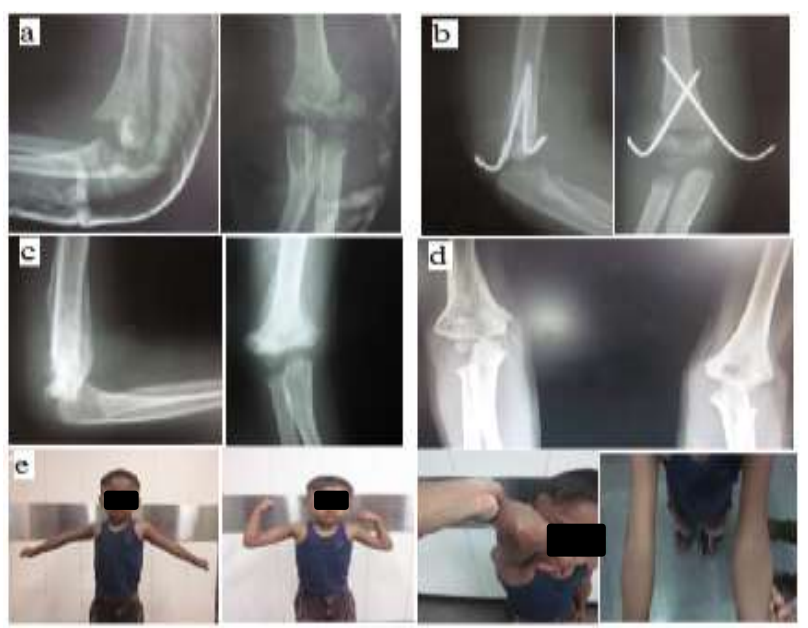

Figure 2: $2^{1 / 2}$ year old male child with right sided close type III supracondylar humerus fracture 10 days old treated with open reduction and internal fixation by using cross $k$ wires. (a) preoperative $\mathbf{X}$-ray, (b) immediate postoperative X-ray, (c) X-ray after 3 month follow up, (d) X-ray after 9 month follow up with calculated Baumann's angle $\&$ comparison with normal side, (e) clinical pictures of flex-ext movement, scar and carrying angle after 9 month follow up.

\section{Statistical analysis}

All the values are expressed as mean \pm SD. Pearson's chisquare tests and unpaired t-tests for overall comparison between two groups were used in significance analysis. $\mathrm{P}$ values $<0.05$ were considered as statistically significant.

\section{RESULTS}

50 cases of Gartland 3 supracondylar fracture humerus were operated, 25 by closed reduction (group 1) and 25 by open reduction (group 2). The demographic profile of the patients was not statistically significant when compared between the two groups as given in Table 2 . The mean age group was 6.84 years in group 1 and 6.64 years in group 2. Fractures were more in boys compared to girls in both the groups. Most of the fractures in both the groups were seen on left side.

Table 2: Comparison of demographic profile of patients between two groups.

\begin{tabular}{|c|c|c|c|}
\hline Parameter & Group 1 & Group 2 & $\begin{array}{l}P \text { - } \\
\text { value }\end{array}$ \\
\hline $\begin{array}{l}\text { No. of } \\
\text { patients }\end{array}$ & 25 & 25 & \\
\hline \multicolumn{4}{|l|}{ Age (years) } \\
\hline Mean & 6.84 & 6.64 & \multirow[b]{3}{*}{0.810} \\
\hline SD & 2.58 & 3.23 & \\
\hline Range & $2-12$ & $1-12$ & \\
\hline \multicolumn{3}{|l|}{$\operatorname{Sex}(\%)$} & \multirow{3}{*}{0.059} \\
\hline M & $15(60 \%)$ & $21(84 \%)$ & \\
\hline $\mathbf{F}$ & $10(40 \%)$ & $4(16 \%)$ & \\
\hline \multicolumn{3}{|l|}{ Side (\%) } & \multirow[b]{3}{*}{0.774} \\
\hline $\mathbf{R}$ & $10(40 \%)$ & $11(44 \%)$ & \\
\hline $\mathbf{L}$ & $15(60 \%)$ & $14(56 \%)$ & \\
\hline
\end{tabular}

As given in Figure 3, most of injuries (68\% of total cases) were due to fall from height in both the groups but this difference was not significant.

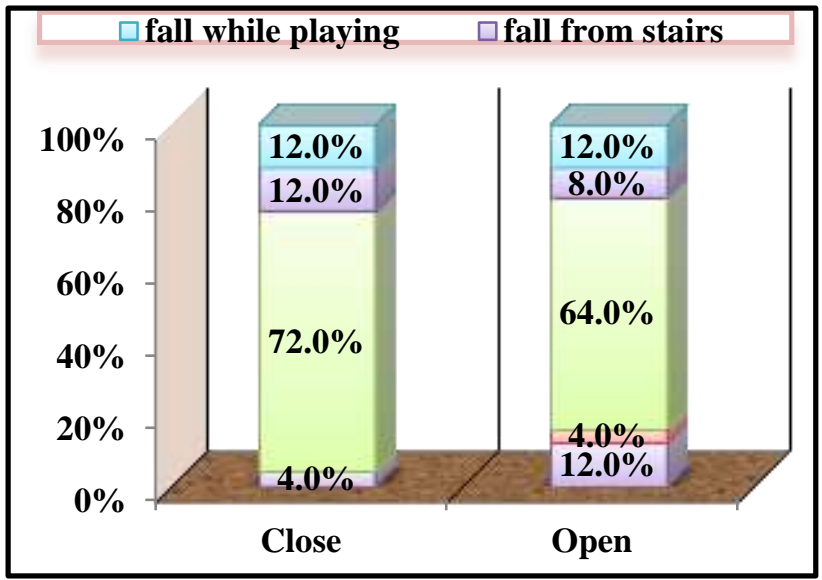

Figure 3: Distribution of study group as per mode of injury. 
Table 3 explains displacement of distal fragments in both the groups. Posteromedial displacement of distal fragment was present in $80 \%$ (40 patients) of total cases, of which $84 \%$ (21 patients) in group 1 and $76 \%$ (19 patients) in group 2. Other patients had posterolateral displacement. Results are comparable in both study group but statistically were not significant.

Table 3: Comparison of distal fragment displacement among the study groups.

\begin{tabular}{|c|c|c|c|c|}
\hline \multicolumn{3}{|c|}{ Displacement } & \multirow{2}{*}{ Total } & \multirow[b]{2}{*}{ P-value } \\
\hline Groups & $\begin{array}{l}\text { Postero } \\
\text {-lateral }\end{array}$ & $\begin{array}{l}\text { Postero- } \\
\text { medial }\end{array}$ & & \\
\hline $\begin{array}{l}\text { Group } \\
1\end{array}$ & $16.0 \%$ & $84.0 \%$ & $100.0 \%$ & \multirow{3}{*}{0.480} \\
\hline $\begin{array}{l}\text { Group } \\
2\end{array}$ & $24.0 \%$ & $76.0 \%$ & $100.0 \%$ & \\
\hline Total & $20.0 \%$ & $80.0 \%$ & $100.0 \%$ & \\
\hline
\end{tabular}

The average duration between time of trauma and time of surgery in closed reduction with group 1 was 0.49 days and for group 2 was 1.14 days, but difference was not significant. A significant difference was observed between two groups in average number of shoots of image intensifier. It was 21.08 in group 1 and 7.04 in group 2 as shown in Table 4.

Table 4: Comparison of time taken to do surgery and number of shoots with radiation between two groups.

\begin{tabular}{|c|c|c|c|}
\hline & Mean & S. D. & P value \\
\hline \multicolumn{4}{|c|}{ Time since injury (Days) } \\
\hline Group 1 & 0.49 & 0.44 & \multirow{2}{*}{0.119} \\
\hline Group 2 & 1.14 & 2.00 & \\
\hline \multicolumn{4}{|c|}{ Image intensifier shoots in number } \\
\hline Group 1 & 21.08 & 4.51 & \multirow{2}{*}{0.000} \\
\hline Group 2 & 7.04 & 2.07 & \\
\hline
\end{tabular}

Table 5: Comparison of both study group in relation to time required for surgery, healing and ROM.

\begin{tabular}{|c|c|c|c|}
\hline & Mean & S. D. & P-value \\
\hline \multicolumn{4}{|c|}{ Duration of surgery (in hours) } \\
\hline Group 1 & 45.8 & 8.98 & \multirow{2}{*}{0.0001} \\
\hline Group 2 & 82 & 9.13 & \\
\hline \multicolumn{3}{|c|}{ Duration of healing (months) } & \multirow{3}{*}{0.000} \\
\hline Group 1 & 3.00 & 0.00 & \\
\hline Group 2 & 3.40 & 0.50 & \\
\hline \multicolumn{3}{|c|}{ Duration for optimal ROM (in days) } & \multirow{3}{*}{0.196} \\
\hline Group 1 & 33.32 & 5.41 & \\
\hline Group 2 & 35.48 & 6.22 & \\
\hline
\end{tabular}

As per results shown in Table 5, there is statistically significant difference in comparison of duration of surgery among both study groups. Closed reduction required less duration for surgery. Mean duration for healing of fracture in closed reduction group is 3 months and in open reduction group is 3.40 months, there is statistically significant difference between two study group. This is because of evacuation of fracture site hematoma during open reduction method to achieve anatomical reduction. In this study, mean time required to attain optimal ROM in group 1 is 26.12 days and in group 2 is 34.28 days, the difference is statistically not significant. Duration required in group 2 is more as compared to group 1 and this is because of delay in starting range of motion exercises by patients in open reduction group.

Mean change in Baumann's angle (BA), carrying angle and range of motion (ROM) as compared to normal side in both the groups after $3^{\text {rd }}$ and $9^{\text {th }}$ month of follow ups was found to be not statistically significant as given in Table 6.

Table 6: Statistical comparison related to loss of BA, CA and ROM after 3 and 9 months.

\begin{tabular}{|c|c|c|c|c|c|c|c|c|}
\hline Groups & After 3 months & Mean & S. D. & P value & After 9 months & Mean & S. D. & P value \\
\hline Group 1 & \multirow{2}{*}{ Change BA } & 2.28 & 1.40 & \multirow{2}{*}{0.160} & \multirow{2}{*}{ Change BA } & 1.88 & 0.93 & \multirow{2}{*}{0.739} \\
\hline Group 2 & & 2.92 & 1.75 & & & 2.00 & 1.53 & \\
\hline Group 1 & \multirow{2}{*}{ Change CA } & 1.40 & 1.15 & \multirow{2}{*}{0.195} & \multirow{2}{*}{ Change CA } & 1.28 & 0.89 & \multirow{2}{*}{0.121} \\
\hline Group 2 & & 1.84 & 1.21 & & & 1.68 & 0.90 & \\
\hline Group 1 & \multirow{2}{*}{ Change in ROM } & 12.60 & 3.85 & \multirow{2}{*}{0.174} & \multirow{2}{*}{ Change in ROM } & 6.40 & 3.69 & \multirow{2}{*}{0.153} \\
\hline Group 2 & & 14.40 & 5.27 & & & 8.20 & 4.97 & \\
\hline
\end{tabular}

Table 7: Results according to Flynn's criteria among the study groups.

\begin{tabular}{|llllll|}
\hline Flynn's criteria & Overall result (after $\mathbf{9}$ months of F/U) & & Total \\
\hline Loss of Carrying angle in degrees & $>15$ & $5-10$ & $10-15$ & $<5$ & \\
\hline Loss of ROM (flex-ext ) in degrees & $>15$ & $5-10$ & $10-15$ & $<5$ & \\
\hline Results & Poor & Good & Fair & Excellent & \\
\hline Group 1 & $0.0 \%$ & $24.0 \%$ & $16.0 \%$ & $60.0 \%$ & $100.0 \%$ \\
\hline Group 2 & $4.0 \%$ & $28.0 \%$ & $16.0 \%$ & $52.0 \%$ & $100.0 \%$ \\
\hline total & $2.0 \%$ & $26.0 \%$ & $16.0 \%$ & $56.0 \%$ & $100.0 \%$ \\
\hline
\end{tabular}


Table 8: Comparison of postoperative complications between two study groups.

\begin{tabular}{|llllll|}
\hline Groups & No. of patients & Ulnar nerve injury & & \multicolumn{2}{c|}{$\begin{array}{l}\text { Postperative wound+pin track } \\
\text { infection }\end{array}$} \\
& & Ulnar nerve palsy (\%) & Nil (\%) & Infection & Nil (\%) \\
\hline Group 1 & 25 & $3(12)$ & $22(88)$ & $1(4)$ & $24(96)$ \\
\hline Group 2 & 25 & $1(4)$ & $24(96)$ & $1(4)$ & $24(96)$ \\
\hline Total & 50 & $4(8)$ & $46(92)$ & $2(4)$ & $48(96)$ \\
\hline P value & & 0.297 & & 0.368 & \\
\hline
\end{tabular}

Table 9: Comparison in respect of overall satisfaction score.

\begin{tabular}{|lllll|}
\hline Perspective & Evaluator mean & & SD & \\
\hline Satisfaction Score $\mathbf{( 0}-\mathbf{1 0})$ & Blinded & Patients & Blinded & Patients \\
\hline Group 1 & 9.16 & 8.92 & 0.85 & 0.81 \\
\hline Group 2 & 8.88 & 8.58 & 0.88 & 0.78 \\
\hline P value & 0.2587 & 0.1448 & & \\
\hline
\end{tabular}

As per data given in Table 7, after 9 months of follow up $(\mathrm{F} / \mathrm{U})$ overall result according to Flynn's criteria was $60 \%$ excellent in group 1 as compared to $52 \%$ in group 2 . Also good, fair and poor results in each group were comparable to each other without any statistically significant difference $(\mathrm{p}=0.748)$.

Table 8 shows the non-statistical significance for postoperative complications among the study groups. Ulnar nerve palsy occurs in $12 \%$ cases in group 1 , and $4 \%$ cases in group 2. A combination of postoperative wound infection and pin tract infection was observed $4 \%$ in each study group.

Mean satisfaction score in group 1, blinded was 9.16 and patient perspective was 8.92 out of 10 where as in group 2 , blinded 8.88 and patient perspective was 8.58 out of 10. Overall satisfaction score in group 1 is better than group 2 as given in Table 9.

\section{DISCUSSION}

Supracondylar fractures of humerus is a common fractures seen in children. ${ }^{12}$ The important goals of the treatment are full recovery of elbow movements, achieving normal cosmetic view of elbow, protecting the patient from neurovascular complications that may occur. ${ }^{13}$ These types of fractures are common under the age group of 5-12 years. In our study, the age distribution is from 1 to 12 and the mean age is 6.64-6.68 years. In particular, incidence peaks between the ages of 5-7 have been reported. ${ }^{12,14,15}$ Supracondylar fractures of humerus are common in boys compared to girls. In our series, $72 \%$ were boys and $28 \%$ were girls. These results are consistent with previous literature. ${ }^{12,14,16}$ In our study, the fractures are more common on left side as observed i.e. $58 \%$ in total of patients $(60 \%$ in group 1 and $56 \%$ in group 2). These results were also more common in previous studies. ${ }^{14,16,17}$
In the present study, $72 \%$ of total cases had mode of injury as fall from height among group 1, as compared to $64 \%$ among group 2 . Remaining cases had injury because of fall from bicycle, fall from bike and fall while playing, all these mode of injury involved mechanism of fall from height with extended elbow. This finding correlates to the observation of previous studies that, fall from height with elbow in extension is commoner mode of injury for supracondylar humerus fractures. ${ }^{18}$

Posteromedial displacement of distal fragment is common due to more medial insertion of triceps and pull of biceps more on medial side. In this study posteromedial displacement were noted in in $80 \%$ patients and posterolateral displacement in $20 \%$ patients. It was observed that incidence of posteromedial displacement as compared to posterolateral was $79 \%$ and $21 \%$ in a study done by Kaewpornsawan. ${ }^{19}$

Mean time lag between time of trauma to time of surgery for type-III supracondylar humerus fracture is 0.49 days in group 1 and 1.14 days in group 2. In group 2 time lag is more as compared to group 1. This is because of group 2 contained more old fractures as these fracture not get reduced by close means. In this study, image intensifier shoots are 21.08, more for group 1 as compared to 7.04 in group 2. Comparison of radiation exposure in each group has not been studied previously but we have found in our study that, radiation exposure is more in patients treated by closed reduction with fixation and is statistically significant. Therefore there is need of radiation protection whenever operating by closed reduction method. If there is not an image intensifier in the operating room open reduction and pinning offers an alternative treatment for decreasing the surgical time and complication without much radiation exposure.

Mean loss of carrying angle in our study was 1.28 degrees after 9 months in patients operated by closed reduction with fixation method and 1.68 degrees after 9 months in patients operated by open reduction with 
fixation methods. There is no any statistically significant difference in loss of carrying angle that is cosmetic appearance, between two study groups, also there is no relation of carrying angle change to Baumann's angle change.

Baumann angle is an important angle in control of the reduction. Normal range is between 64 and $81^{0} .^{20}$ The mean loss of Baumann's angle is 1.88 degrees and 2.00 degrees after 9 months in patients operated by closed and open reduction with fixation method after 9 months respectively. Comparison of improvement of Baumann's angle on long term follow up has not been studied previously, but we have found in our study that Baumann's angle approaches towards normal range as non-affected elbow for same patient from 3 month to 9 months of follow up in open reduction group and it is statistically significant than that of closed reduction group, this signifies that varus or valgus angulation remodel over a period but rotational angulation do not remodel. Due to accurate anatomical reduction as possible while open reduction remodelling at fracture site is relatively faster and better than that of close reduction. In this study, mean loss of range of motion (flex-ext) is 6.40 degrees and 8.20 degrees after 9 months in patients operated by closed reduction and open reduction with fixation methods respectively. This is due to incision scar related delay, to start range of motion exercise by patients in open reduction group.

Mean duration for healing of fracture in group 1 is 3 months and in group 2 is 3.40 months. This is because of evacuation of fracture site hematoma during open reduction method to achieve anatomical reduction. The ultimate union rate is 100 percent in each group. But in a study done by Ozkoc et al it was 4.8 and 5.3 months in group 1 and group 2 respecively. ${ }^{21}$

In our study functional outcome of supracondylar fracture in children was measured in terms of Flynn's criteria. A higher satisfaction score with better cosmetic results are obtained in group 1 as there is no obvious scar and early gain of optimum range of motion in group 1. But there is no any statistically significant difference between both study groups over a period of time. In group 1 excellent results were obtained in $21(84 \%)$ and poor in $4(16 \%)$ patients whereas in group 2 it was excellent in $20(80 \%)$ and poor in $5(20 \%)$ patients. The results of present study was comparable with those of other series. ${ }^{22,23}$

The common complications observed in our study in both the groups are iatrogenic ulnar nerve injury and postoperative wound infection. It was observed that ulnar nerve injuries are more common with closed reduction procedure. In group 1, $12 \%$ of patients had ulnar nerve injury and $4 \%$ in group 2 . All nerve injuries recover after 3 months. These observations are comparable with the studies of Kaewpornsawan et al and Ozkocet al. ${ }^{19,21}$ Slight more occurrence of nerve injuries is due to blind insertion of k-wire from medial epicondyle.
Mean satisfaction score is subjective finding. Overall satisfaction score by patient's perspective for group 1 (8.92) is better than that of group 2 (8.58), but the difference is not significant between two groups. According to the results of Kaewpornsawan et al it was 9.2 in group 1 and 8.6 in group $2 .^{19}$

\section{CONCLUSION}

Early closed reduction and fixation is a gold standard treatment for extension type III supracondylar humerus fractures in children. Because of a higher satisfaction score with better cosmetic results, less surgical trauma to tissues, less postoperative stiffness and cost effective. Bu, if there is no image intensifier in the operating room, open reduction and fixation offer an alternative treatment for decreasing the surgical time and complication with comparable good anatomical and functional results.

Funding: No funding sources

Conflict of interest: None declared

Ethical approval: The study was approved by the institutional ethics committee

\section{REFERENCES}

1. Cheng JC, Ng BK, Ying SY, Lam PK. A 10 year study of the changes in the pattern and treatment of 6,493 fractures. J Paediatr orthop. 1999;19(3):34450.

2. Dimeglio A. Growth in paediatrics orthopaedics. in: Morrissy RT, Weinsten SL, eds. Lovell and Winters's paediatrics orthopaedics. 6th edition. philadelphia: Lippincott Williams and wilkins; 2006: 35 -65.

3. Boyd HB, Altenberg AR. fractures about elbow in childrens. Arch surg. 1944;49:213.

4. Cheng GC, Lam TP, Maffulli N. Epidemiological features of supracondylar fractures of the humerus in Chinese childrens. J paediatrics orthopaedics B. 2001;10(1):63-7.

5. Mahan ST, May CD, Kocher MS. operative management of displaced flexion supracondylar humerus fractures in children. J Paediatr Orthop. 2007;27(5):551-6.

6. Farnsworth CL, Silva PD, Mubarak SJ. Etiology of supracondylar humerus fractures. J Paediatr Orthop. 1998;18(1):38-42.

7. Houshian S, Mehdi B, Larsen MS. The epidemiology of elbow fracture in the childrens: analysis of 355 fractures, with special reference to supracondylar humerus fractures. J Orthop Sci. 2001;6:312-5.

8. Topping RE, Blanco JS, Davis TJ. Clinical evaluation of crossed pin versus lateral pin fixation in displaced supracondylar humerus fracture. J Paediatr Orthop. 1995;15(4):435-9.

9. Rowell PJW. Arterial occlusion in juvenile humeral supracondylar humeral fractures. Injury. 1974;6:254-6. 
10. Hammond G. The management of S.C. fractures of the humerus in children. Surgical Clinics of N.A. 1952;32(2):747.

11. Dinielsson L, Pettersson H. Open reduction and pin fixation of severely displaced S.C. fractures of the humerus in children. Acta Orthop Scand. 1980;54:249.

12. Kasser JR, Beaty JH. Supracondylar fractures of the distal humerus. Chapter14. In: Rockwood and Wilkins Fractures in Children. 6th edition. Philadelphia: Lippincott Williams and Wilkins; 2006: 543-589.

13. Aslan A, Konya MN, Özdemir A, Yorgancigil H, Maralcan G, Uysal E. Open reduction and pinning for the treatment of Gartland extension type III supracondylar humeral fractures in children. Strategies Trauma Limb Reconstr. 2014;9(2):79-88.

14. Yousri T, Tarassoli P, Whitehouse M, Monsell F, Khan WS. Systematic review of randomized controlled trials comparing efficacy of crossed versus lateral $\mathrm{K}$-wire fixation in extension type Gartland type III supracondylar fractures of the humerus in children. Ortop Traumatol Rehabil. 2012;14(5):397-405.

15. Pretell-Mazzini J, Rodriguez-Martin J, AuñonMartin I, Zafra-Jimenez JA. Controversial topics in the management of displaced supracondylar humerus fractures in children. Strategies Trauma Limb Reconstr. 2011;6:43-50.

16. Mazda K, Boggione C, Fitoussi F, Penneçot GF. Systematic pinning of displaced extension-type supracondylar fractures of the humerus in children. A prospective study of 116 consecutive patients. J Bone Joint Surg. 2001;83:888-93.

17. Mehserle WL, Meehan PL. Treatment of the displaced supracondylar fracture of the humerus (Type 3) with closed reduction and percutaneous cross-pin fixation. J Pediatr Orthop. 1991;11:70511.

18. Sharma A, Walia JPS, Brar BS, Sethi S. Early results of displaced supracondylar fractures of humerus in children treated by closed reduction and percutaneous pinning. Indian $\mathbf{J}$ Orthop. 2015;49(5):529-35.

19. Kaewpornsawan K. Comparison between closed reduction with percutaneous pinning and open reduction with pinning in chidrens with closed totally displaced supracondylar humeral fractures: a randomised controlled trial. J Paediatr Orthop. 2001;(10):131-7.

20. Aronson DD, Prager BI. Supracondylar fractures of the humerus in children. Clin Orthop Relat Res. 1987;219:174-84.

21. Ozkoc G, Gonc U, Kayaalp A, Teker K, Peker TT. Displaced supracondylar humeral fractures in childrens: open reduction vs. closed reduction and pinning. Arch Orthop Trauma Surg. 2004;124:54751.

22. Yadav UB, Singhal R, Tonk G, Aggarwal T, Verma AN. Crossed pin fixation in displaced supracondylar humerus fractures in children. Traumatol. 2004;38:166-9.

23. Sial NA, Yasin A, Rashid A. Supracondylar humerus fractures outcome of open reduction and percutaneous crossed pin fixation. Prof Med J. 2011;18(1):147-53.

24. Mehserle WL, Meehan PL. Treatment of the displaced supracondylar fracture of the humerus (type III) with closed reduction and percutaneous cross-pin fixation. J Pediatr Orthop. 1991;11(6):705-11.

Cite this article as: Keche NJ, Kale AB, Sheth BA, Rathod AK. Comparative analysis of surgical outcome of treatment of supracondylar humerus fractures Gartland's extension type III by using closed reduction and $\mathrm{K}$-wire fixation versus open reduction and $\mathrm{K}-$ wire fixation method. Int J Res Orthop 2017;3:271-7. 